\title{
Phytochemical screening, phenolic content and antioxidant activity of Lavandula species extracts from Algeria
}

\author{
Farah Haddouchi' (D), Tarik Mohammed Chaouche ${ }^{1}$ (D) Meriem Saker ${ }^{2}$ (D), Imane Ghellai ${ }^{1}$ (D), \\ Ouhiba Boudjemai' (1) \\ ${ }^{1}$ Abou Bekr Belkaïd University, Department of Biology, Laboratory of Natural Products, Tlemcen, Algeria \\ ${ }^{2}$ Abou Bekr BelkaïdUniversity,Department of Biology Laboratory of Physiology, Physiopathology and Biochemistry of \\ Nutrition, Tlemcen, Algeria
}

ORCID IDs of the authors: F.H. 0000-0002-1204-3337; T.M.C. 0000-0002-8631-2587; M.S. 0000-0003-3194-5616;

I.G. 0000-0003-3229-7147; 0.B. 0000-0003-2899-2323

Cite this article as: Haddouchi, F., Chaouche T.M., Saker M, Ghellail, I., \& Boudjemail, O. (2021). Phytochemical screening, phenolic content and antioxidant activity of Lavandula species extracts from Algeria. Istanbul Journal of Pharmacy, 51(1), $111-117$.

\begin{abstract}
Background and Aims: We are interested in the comparison of phytochemical screening, the estimation of the phenolic content and the antioxidant activity of the leaves and flowers of three species of Lavandula (L. dentata, L. multifida, and L. stoechas) from the Tlemcen region (Algeria).

Methods: The preparations of the hydro-methanolic extracts were carried out by maceration. The latter in order to quantify the phenolic compounds and to evaluate the antioxidant activity in vitro by trapping the $\mathrm{DPPH}^{\circ}$ radical and iron reducer. Results: Phytochemical tests reveal the presence of tannins and flavonoids in all extracts with varying intensities. The determination of total phenols by the Folin ciocalteu method shows that the extract from the leaves of $L$. multifida is the richest in total phenols (23.11 mg EAG/g DW) and has the most important important reducing power $(E C 50=343 \pm 10 \mu \mathrm{g} / \mathrm{ml})$ and inhibition of DPPH radical activity $(I C 50=7.43 \mu \mathrm{g} / \mathrm{mL})$.

Conclusion: In this context, the results presented deduce that these plants are a promising source of phenolic compounds. Biological studies are needed to elucidate and conclude the effectiveness of these plants, which can be a challenge for new food and cosmetic products.
\end{abstract}

Keywords: Lavandula, Phytochemical screening, phenolic compounds, Antioxidant activity

\section{INTRODUCTION}

Investigations of medicinal plants are still under development. Because they have been recognised as an essential supply for healthcare treatments; so, it can be stated with all certainty that in recent years, there is a growing interest in the subject of natural active substances contained in herbs (Kala 2015; Adaszyńska-Skwirzyńska \& Dzięcioł 2017). The efficacy of the plants in the treatment of different human diseases has been attributed to the presence of different active compounds, principally phenolic derivatives. These compounds have been well-reported to exert antioxidant properties. They may prevent the damage caused by reactive oxygen species (Algieri et al., 2016). Lamiaceae is one of the largest families of flowering plants comprising about 250 genera and over 7,000 species (Napoli, Siracusa, \& Ruberto, 2020). The Lavandula genus is an important member of this family (Canlı, Yetgin, Benek, Bozyel, \& Murat Altuner, 2019), it is native to the Mediterranean region and grows as high as 1-2m with ever- 
green leaves (Soheili \& Salami, 2019). Lavandula is rich in a wide variety of secondary metabolites, such as essential oils, coumarins and phenolic compounds (Panuccio, Fazio, Papalia, \& Barreca, 2016). It is used to treat superficial wounds and burns and has sedative, antibacterial, anti-fungal, antidepressant and anti-inflammatory effects (Soheili \& Salami, 2019). The flowers and leaves of lavender either in the form of essential oil mostly, or different forms of extracts are extensively used in cosmetics, hygiene products, food industry, perfumery and pharmaceutical preparations with high industrial value (Panuccio et al., 2016; Canlı et al., 2019; Soheili \& Salami, 2019). This gender consists of 47 species of small green shrubs having aromatic foliage and flowers (Canlı et al. 2019).

This work based its interest on three species of lavender used in traditional medicine in Algeria. Lavandula multifida L. , which is often used to treat rheumatism, also has hypoglycemic and anti-inflammatory properties (El-Hilaly, Hmammouchi, \& Lyoussi, 2003; Sosa et al. 2005). L. stoechas L. is a species applied to treat epilepsy and headaches, it has antimicrobial, analgesic, antiseptic and antispasmodic effects (Amara et al. 2017; Bousta \& Farah 2020). Another species L. dentata L. has carminative and nervous properties; its essential oils have been used as a tonic against vertigo, nervous trembling, weakness, spasms and colic (Dif, Benyahia, Benali, Rahmani, \& Bouazza, 2017). The present study aimed to quantify the phenolic compounds contained in the hydromethanolic extracts of $L$. dentate, $L$. multifida, and L. stoechas, and to evaluate their antioxidant capacities by $\mathrm{DPPH}^{\circ}$ assay and iron reduction, in order to show possible differences in antioxidant content and improve the knowledge of bioactive compounds, which may be helpful for therapeutic and pharmaceutical applications.

\section{MATERIALS AND METHODS}

\section{Plant material}

Lavandula dentata, L. stoechas and L. multifida, were harvested in February 2020 in the Ghazaouet region, wilaya of Tlemcen (North-West of Algeria). They were identified in the Laboratory of Natural Products, the Department of Biology, in the University of Tlemcen, Algeria. Voucher specimens were deposited at the Herbarium of the Laboratory. The leaves and flowers of each plant were separated and dried in a dark and dry place. The samples were transformed into powder using an electric mill.

\section{Preparation of hydro-methanolic extracts}

The preparations of the hydro-methanolic extracts were carried out by maceration for 24 hours of $10 \mathrm{~g}$ of the plant powder in $200 \mathrm{~mL}$ of methanol-water (70-30). After filtration, the extracts were evaporated at $45^{\circ} \mathrm{C}$ under reduced pressure.

The yield of the plants in dry extract was determined by calculating the following ratio: Yield\% $=[$ P1-P2 / P3 $] \times 100$

P1: Weight of the flask after evaporation, P2: Weight of the empty flask, P3: Weight of the starting dry plant material.

The dry extracts were taken up in a few millilitres of methanol for phytochemical tests, dosages and assessments of antioxidant activity.

\section{Phytochemical tests of flavonoids and tannins}

In order to highlight the presence or absence of certain compounds belonging to the chemical families of secondary metabolites, specific phytochemical tests were carried out based on color, turbidity or precipitation reactions, using the methods described in the literature (Haddouchi, Chaouche, \& Nourdinne, 2018).

\section{Detection of flavonoids}

Ten drops of concentrated hydrochloric acid $(\mathrm{HCl})$ and a few milligrams of magnesium turnings were added to $0.5 \mathrm{~mL}$ of each extract. The pink red or yellow coloration, after 3 min of incubation at room temperature, indicates the presence of flavonoids.

\section{Detection of tannins}

Eight drops of a dilute solution of ferric chloride $\left(\mathrm{FeCl}_{3}\right)$ at $1 \%$ were added to $0.5 \mathrm{~mL}$ of each extract. After a few minutes of incubation at room temperature, the ferric chloride develops a greenish coloration, which indicates the presence of catechic tannins or a blue-blackish one, which reveals the existence of gallic tannins.

\section{Determination of total phenol contents}

One hundred $\mu \mathrm{L}$ of each extract at a concentration of $1 \mathrm{mg} /$ $\mathrm{ml}$, and mixed with $2 \mathrm{~mL}$ of a sodium carbonate (2\%) solution were freshly prepared, the whole was agitated with a vortex. After $5 \mathrm{~min}, 100 \mu \mathrm{L}$ of the Folin-Ciocalteu diluted reagent $(1 / 20)$ was added, the mixture was incubated in total darkness for $30 \mathrm{~min}$ at room temperature, the absorbance was read at $700 \mathrm{~nm}$. Different concentrations of gallic acid were used to prepare a calibration curve. The results were expressed as milligram gallic acid equivalents (GAE)/g DW (Chaouche, Haddouchi, Boudjemai, \& Ghellai, 2020).

\section{In vitro evaluation of antioxidant activity Scavenging of the free radical DPPH ${ }^{\circ}$}

At different concentrations, $50 \mu \mathrm{L}$ of each extract was added to $1950 \mu \mathrm{L}$ of a methanolic solution of 2,2-diphenyl-1-picrylhydrazyl $\left(\mathrm{DPPH}^{\circ}\right)$ at $6.3410^{-5} \mathrm{M}$. For each concentration, a blank was prepared. A negative control was prepared, in parallel, while mixing $50 \mu \mathrm{L}$ of methanol with $1950 \mu \mathrm{L}$ of a methanolic solution of $\mathrm{DPPH}^{\circ}$ at the same used concentration. After incubation in the dark for 30 minutes and at room temperature, the reduction in $\mathrm{DPPH}^{\circ}$ was accompanied by a change of color from purple to yellow in the solution. The absorbances were read at $515 \mathrm{~nm}$ using a spectrophotometer. The positive control used was butylated hydroxyanisole (BHA), and the radical scavenging activity was calculated as a percentage of DPPH discoloration using the equation: $\mathrm{DPPH}^{\circ}$ radical scavenging $(\%)=[(\mathrm{A} 0-\mathrm{A} 1 / \mathrm{A} 0] \times 100$ Where $\mathrm{A} 0$ and $\mathrm{A} 1$ are the absorbance at $30 \mathrm{~min}$ of the positive control and the extract, respectively. The anti-radical activity was expressed as $I C_{50}(\mu \mathrm{g} / \mathrm{mL})$, this was the extract concentration required to cause a reduction of $50 \%$ to absorbance at $517 \mathrm{~nm}$. A lower $I_{50}$ value corresponds to the extract effectiveness (Chaouche et al. 2015).

\section{Ferric reducing antioxidant potential (FRAP)}

After adding $1 \mathrm{~mL}$ of each extract at different concentrations with $2.5 \mathrm{~mL}$ of $0.2 \mathrm{M}$ phosphate buffer at $\mathrm{pH}=6.6$ and $2.5 \mathrm{~mL}$ 
of a $1 \%$ potassium ferricyanide solution, the obtained mixture was incubated for 20 minutes at $50^{\circ} \mathrm{C}$, and then $2.5 \mathrm{~mL}$ of $10 \%$ trichloroacetic acid was added to stop the reaction. The mixture was centrifuged at $650 \mathrm{~g}$ for ten minutes at room temperature and $2.5 \mathrm{~mL}$ of the supernatant were added to $2.5 \mathrm{~mL}$ of distilled water and $0.5 \mathrm{~mL}$ of $0.1 \%$ iron chloride. The absorbance was read at $700 \mathrm{~nm}$ against a blank. The results make it possible to calculate the effective concentration $\left(\mathrm{EC}_{50}\right)$, which is the extract concentration corresponding to an absorbance equal to 0.5 , the linear regression curve (optics density as a function of the different concentrations). The extract activity was finally compared with that of the positive control (BHA) (Chaouche et al. 2015).

\section{Statistical analysis method should be written}

Values shown in tables were means \pm standard deviations of three parallel measurements. IC50 and EC 50 values were calculated from linear regression analysis.

\section{RESULTS}

\section{Yields of hydro-methanolic extracts}

The extracts were prepared by maceration for 24 hours in methanol-water (70/30); the yields of dry extracts are shown in Table 1.

\section{Phytochemical tests}

Specific phytochemical tests were carried out based on staining reactions to highlight the presence or absence of two families of compounds belonging to polyphenols, which are flavonoids and tannins. The results obtained are presented in Table 2.

Phytochemical tests carried out on the extracts of the two parts, leaves and flowers of each studied plant, revealed the

\section{Table 1. The yields obtained from the two parts of} the plants studied.

\begin{tabular}{|lcc|}
\hline & Plants & Yields (\%) \\
\hline Leaves & L. dentata & $21.52 \pm 0.9$ \\
& L. multifda & $12 \pm 0.6$ \\
Flowers & L. stoechas & $18.69 \pm 0.8$ \\
& L. dentata & $14.96 \pm 0.6$ \\
& L. multifida & $10.76 \pm 0.6$ \\
& L. stoechas & $15.54 \pm 0.5$ \\
\hline
\end{tabular}

presence of tannins and flavonoids in all the extracts with varying intensities. For flavonoids, the richest extracts are those of the leaves of L. dentata and L. multifida, with medium intensities. These tests also reveal that all the extracts contain catechic tannins with medium to high intensities, except the extract from the leaves of L. multifida, which contains gallic tannins with a very intense blue-black color.

\section{Total polyphenol content}

The estimation of total polyphenol contents was carried out by the Folin-Ciocalteu spectrophotometric method. The results obtained are expressed in milligrams of gallic acid equivalent per gram of dry matter (mg GAE/g DW) (Table 3).

Variable contents are found in the numerous hydro-methanolic extracts of the plants studied. The highest content was recorded for the extract of the leaves of L. multifida $(23 \pm 1.1$ mg EAG/g DW). Significant contents have been observed in extracts of leaves of $L$. stoechas (18 $1.4 \mathrm{mg} E A G / g$ DW), $L$. dentata (15.8 $\pm 0.9 \mathrm{mg} E A G / g$ DW) and in extracts of flowers of L. stoechas (17.8 $\pm 1.6 \mathrm{mg} \mathrm{EAG/g} \mathrm{DW)} \mathrm{and} \mathrm{L.} \mathrm{dentata} \mathrm{(16.4 \pm 0.5}$ $\mathrm{mg}$ EAG/g DW). The extract from the flowers of $L$. multifida has

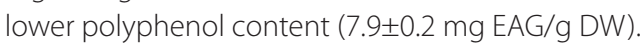

\section{Assessment of antioxidant activity}

The evaluation of the antioxidant power of the extracts of our plants was determined by two in vitro methods, the trapping of the free radical $\mathrm{DPPH}^{\circ}$ and iron reduction.

\section{Trapping of the free radical DPPH}

The results obtained for the positive control, $\mathrm{BHA}$ and for the extracts are expressed as a percentage of inhibition of the free radical DPPH ${ }^{\circ}$ as a function of the concentrations of extracts (Fig. 1).

The results obtained show that the inhibition percentages increase as a function of the concentration of extracts. The best inhibition percentages are obtained from the extracts of the leaves and flowers of L. multifida, $96.66 \%$ and $90.18 \%$ respectively, at a concentration of $1000 \mathrm{mg} / \mathrm{ml}$. The extracts of $L$. stoechas and L. dentata have interesting inhibition percentages, which are between $64.39 \%$ and $75.45 \%$. The antioxidant activity of the leaves of L. multifida are very close to that of BHA and the flowers are slightly (Statistics should be made, this is not a scientifically relevant comparison) lower. However, the other extracts are significantly lower to that of $\mathrm{BHA}$.

Table 2. Results of phytochemical tests.

\begin{tabular}{|c|c|c|c|c|c|}
\hline & \multirow{2}{*}{ Plants } & \multicolumn{2}{|c|}{ Flavonoids } & \multicolumn{2}{|c|}{ Tannins } \\
\hline & & Intensity & Colour & Intensity & Colour \\
\hline \multirow[t]{3}{*}{ Leaves } & L. dentata & ++ & Yellow & +++ & Green \\
\hline & L. multifida & ++ & Yellow & +++ & Dark blue \\
\hline & L. stoechas & + & Yellow & ++ & Green \\
\hline \multirow[t]{3}{*}{ Flowers } & L. dentata & + & Yellow & ++ & Green \\
\hline & L. multifida & + & Yellow & +++ & Green \\
\hline & L. stoechas & + & Yellow & +++ & Green \\
\hline
\end{tabular}




\section{Table 3. Total phenol content in the hydro- methanolic extracts of the plants studied, expressed in (mg EAG/g DM) and in (mg EAG/g extract).}

\begin{tabular}{|llc|}
\hline \multicolumn{1}{|c}{ Leaves } & Plants & Polyphenols (mg EAG/g DW) \\
\hline \multirow{3}{*}{ Flowers } & L. dentata & $15.8 \pm 0.9$ \\
& L. multifda & $23 \pm 1.1$ \\
& L. stoechas & $18 \pm 1.4$ \\
& L. dentata & $16.4 \pm 0.5$ \\
& L.multifida & $7.9 \pm 0.2$ \\
& L. stoechas & $17.8 \pm 1.6$ \\
\hline
\end{tabular}

$\mathrm{mg}$ EAG/g DW: $\mathrm{mg}$ of gallic acid equivalents per gram of dry weight

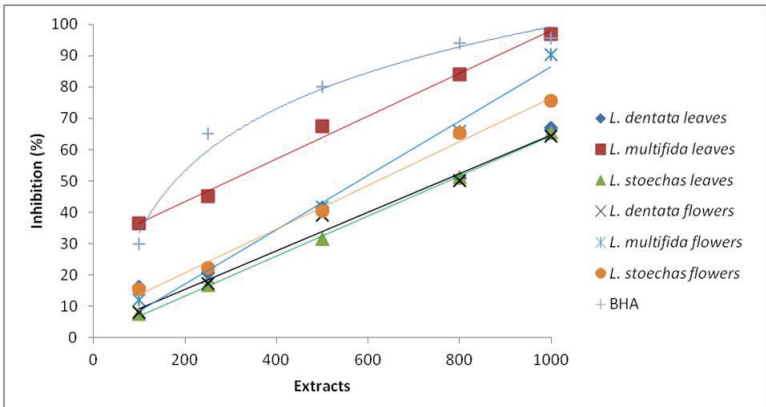

Figure 1. Percentages of inhibition of the $\mathrm{DPPH}^{\circ}$ radical as a function of the different concentrations of the extracts.

The antioxidant power of the different extracts was determined from the inhibitory concentration $I C_{50}$ (Table 4). This is the necessary concentration to inhibit 50\% of the $\mathrm{DPPH}^{\circ}$ radical. The smaller its value, the greater the activity.

For comparative purposes, $\mathrm{BHA}$, which is a standard antioxidant, has significant anti-free radical activity with an $I C_{50}$ value of $150 \mathrm{mg} / \mathrm{mL}$.

According to the $\mathrm{IC}_{50}$ values, the classification of the capacity of the extracts to trap the $\mathrm{DPPH}^{\circ}$ radical is as follows:

BHA $>$ L. multifida leaves $>$ L. multifida flowers $>$ L. stoechas flowers $>L$. dentateleaves $>L$. dentate flowers $>L$. stoechas leaves.

Table 4. DPPH ${ }^{\circ}$ assay expressed as IC50 values $(\mathrm{g} / \mathrm{ml})$ for the hydro-methanolic extracts studied.

\begin{tabular}{|lcc|}
\hline & Extracts & IC $_{50}(\mathbf{g} / \mathrm{ml})$ \\
\hline Leaves & L. dentata & $708 \pm 12$ \\
& L. multifida & $300 \pm 8$ \\
Flowers & L. stoechas & $758 \pm 14$ \\
& L. dentata & $746 \pm 11$ \\
& L. multifida & $571 \pm 9$ \\
BHA & L. stoechas & $612 \pm 10$ \\
\hline
\end{tabular}

$\mathrm{IC}_{50}$ : inhibition concentration $50 \%$; DPPH: 2,2-diphenyl picrylhydrazyl; BHA: Butylated hydroxyanisole
Therefore, extracts from the leaves of L. multifida have the best anti-free radical activity with an $I_{50}$ value of $300 \pm 8 \mathrm{mg} / \mathrm{ml}$, followed by the extract of the flowers of this same plant. This activity remains lower than that of the positive control BHA.

\section{Iron reduction}

This method is based on the reduction capacity of $\mathrm{Fe}^{3+}$ present in the $\mathrm{K}_{3} \mathrm{Fe}(\mathrm{CN})_{6}$ complex into $\mathrm{Fe}^{2+}$. Figure 2 represents the reducing capacity of $\mathrm{BHA}$ and hydromethanolic extracts. This capacity increases as a function of the concentration of the extracts. At a concentration of $1 \mathrm{mg} / \mathrm{ml}$, it is observed that the extract from the leaves of $L$. multifida has the highest absorbance (1.48).

The values of the optical densities obtained made it possible to calculate $\mathrm{EC}_{50}$ of each extract (Table 5). It is the concentration at which the absorbance is equal to 0.5 . The effectiveness of iron reduction is inversely proportional to the $\mathrm{EC}_{50}$ concentration.

For comparative purposes, BHA used as a positive control has an $\mathrm{EC}_{50}$ value of $300 \mathrm{mg} / \mathrm{ml}$.

The classification of the efficiency of iron reduction is as follows: $\mathrm{BHA}>$ L. multifida leaves $>$ L. multifida flowers $>$ L. stoechas flowers $>L$. dentata flowers $>L$. stoechas leaves $>L$. dentate leaves. The most active extracts with the lowest $\mathrm{EC}_{50}$ concentrations were found to be these of $L$. multifida leaves ( $E C_{50} 343 \mathrm{mg} / \mathrm{ml}$ ) and flowers ( $\mathrm{EC}_{50} 396 \mathrm{mg} / \mathrm{ml}$ ).

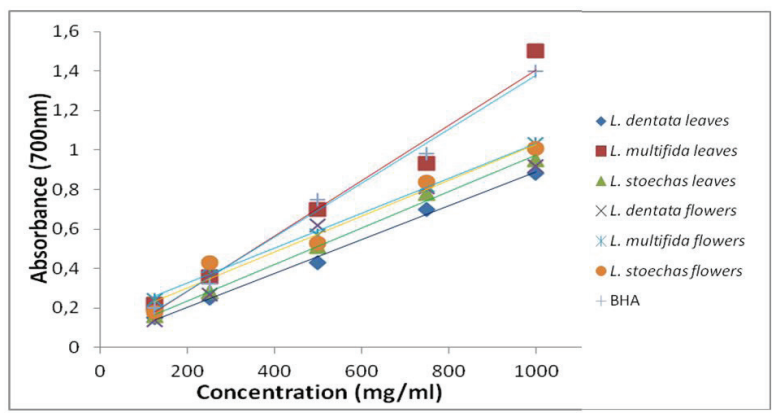

Figure 2. Reducing powers as a function of different concentrations of the extracts.

Table 5: The iron reducing power, expressed as $\mathrm{EC}_{50}$ values $(\mathrm{g} / \mathrm{ml})$ for the hydro-methanolic extracts studied.

\begin{tabular}{|lcc|}
\hline & Extracts & $\mathrm{EC}_{50}(\mathrm{~g} / \mathrm{ml})$ \\
\hline Leaves & L. dentata & $508 \pm 14$ \\
& L. multifida & $343 \pm 10$ \\
& L. stoechas & $485 \pm 12$ \\
Flowers & L. dentata & $467 \pm 12$ \\
& L. multifida & $396 \pm 13$ \\
& L. stoechas & $415 \pm 11$ \\
BHA & $300 \pm 10$ \\
\hline EC 5 : effective concentration at which the absorbance was $0.5 ;$ \\
BHA: Butylated hydroxyanisole
\end{tabular}




\section{DISCUSSION}

Our work is part of the evaluation of the antioxidant activity of the three aromatic plants of the genus Lavandula. The yields of hydromethanolic extracts, obtained by the maceration of the leaves and flowers in methanol-water are different from those found in the two previous works. One was made on the ethanol-water extracts of L. multifida and L. stoechas (Bouharb et al. 2014) and the other on the crude aqueous extracts of $L$. dentata and L. stoechas (Bachiri, Echchegadda, Ibijbijen, \& Nassiri, 2016), and both obtained using the same extraction method. However, it is difficult to compare our results with those of the bibliography, because the method, the solvents and the conditions of extraction, the geographical origin, the conditions of storage and the period of harvest are different.

Phytochemical screening was carried out in order to qualitatively determine the presence of tannins and flavonoids, two important groups of polyphenols, which are present according to the results, obtained in the hydromethanolic extracts of the studied plants with varying intensities. Our results are in agreement with the study carried out by Dif et al. (2017) on the leaves of the three species of Lavandula which provides an important presence of tannins in the leaves of L. dentata and L. multifidi, and a weak presence in the leaves of L. stoechas. While flavonoids are moderately present in the leaves of the three plants studied. Other work carried out on the aerial parts of L. dentata and L. stoechas, shows that the extracts contain tannins and flavonoids with variable intensity (Ramchoun et al. 2009).

The quantitative study of polyphenols revealed that the polyphenol contents are close for the hydromethanolic extracts of the leaves and flowers of L. dentata $(15.8 \pm 0.9$ and $16.4 \pm 0.5 \mathrm{mg}$ EAG/g DW, respectively) and for those of L. stoechas (18 \pm 1.4 and $17.8 \pm 1.6 \mathrm{mg} E A G / g$ DW, respectively). However, the extract from the leaves of L. multifda has a higher content than that of the flowers. It is the richest extract in total polyphenols among the six studied. The total phenol content calculated in mg EAG/g extracted throughout the aerial part of L. multifida, studied by Ramchoun et al. (2009), is 199.16 mg EAG/g extract. This content is very close to that obtained, only, in the leaves of our plant of the same species (192+3.6 mg EAG/g extract).

The polyphenol contents are higher than those found by Dif et al. (2017) in extracts from the leaves of L. multifida (74.74 mg EAG/g extract) and L. stoechas (67.58 mg EAG/g extract) and $L$. dentata (60.84 mg EAG/g extract). Another study shows that the respective contents of total phenols in methanolic extracts of L. stoechas is $25.2 \mathrm{mg} \mathrm{GAE} / \mathrm{g}$ and of L. multifida is 30.8 mg GAE/g (Messaoud, Chograni, \& Boussaid, 2012). In another study, they estimated $184.02 \mathrm{mg}$ EAG/g for L. dentata extract and $64.54 \mathrm{mg} \mathrm{EAG/g}$ for L. stoecha extract, these results cannot be compared with ours (Bachiri et al. 2016). More recently, work carried out on the leaves of $L$. dentata reveals the presence of a higher amount of total polyphenols (39.58 mg EAG/g DW) than ours (Bettaieb Rebey, Bourgou, Saidani Tounsi, Fauconnier, \& Ksouri, 2017) , in another work, the polyphenol content found in the flowers is higher than our results $20.58 \pm 0.18$ (El Hassouni, El Bachiri, \& Belbachir, 2019).
It is difficult to compare our results with this work, because the use of different extraction techniques, different extraction solvents and calibration curves (quercetin, rutin, cathechin) reduce the reliability of the comparison between studies. Studies have shown that the content of phenolic compounds varies considerably from one species to another and within the same species, due to extrinsic factors (temperature, climate, etc.) (Ksouri et al. 2019), genetics (the variety and origin of the species) (Ebrahimzadeh, Pourmorad, \& Bekhradnia, 2008), physiological factors (the degree of maturation of the plant, the nature of the organs) (Maisuthisakul, Pongsawatmanit, \& Gordon, 2007) and the duration of storage.

The antioxidant activity of polyphenols is mainly due to their ability to act as hydrogen donors, reducing agents and radical scavengers. Generally this activity is attributed to the total phenol content and its chemical structure (Messaoud et al. 2012). Consequently, the variation of antioxidant capacity between extracts, observed in our study, can be explained by their polyphenolic content and composition differences. The study by Ramchoun et al. (2009), on the extract from the aerial part of $L$. multifida, the $\mathrm{IC}_{50}$ value is $2.6 \mathrm{mg} / \mathrm{mL}$. A value greater than that of the leaves and flowers of L. multifida, studied in this work. Similarly, the $\mathrm{IC}_{50}$ values, obtained by Dif et al. (2017) from the leaves of the three Lavandula species, are $2.15 \mathrm{mg} / \mathrm{mL}$ for $L$. dentata, $17.36 \mathrm{mg} / \mathrm{mL}$ for L. multifida and $25.52 \mathrm{mg} / \mathrm{mL}$ for $L$. stoechas, significantly higher values than ours. However, the study by Bettaieb et al. (2017) on the leaves, stems and roots of $L$. dentata, reveals $I C_{50}$ values of: $200.8 ; 178.70$ and $50.36 \mathrm{mg} /$ $\mathrm{mL}$, respectively. Therefore a more important activity in flowers, than that of our plant, the $I_{50}$ is 508.10 (El Hassouni et al. 2019). In methanolic extracts of $L$. multifida and $L$. stoechas the $I C_{50}$ are $19.03 \pm 12 I C_{50}, \mathrm{mg} / \mathrm{mL}$ and $34.2 \pm 3.1$ have proved to be more effective than our results (Messaoud et al. 2012). In another work, hydromethanolic extracts of L. stoechas showed a higher in vitro antioxidant activity against the DPPH free radical, than ours (Karabagias, Karabagias, \& Riganakos, 2019).

For the reduction of iron, the $\mathrm{EC}_{50}$ recorded for the extracts of the of L. multifida, L. stoechas and L. dentata leaves and flowers, was very highly active compared to $B H A$, and the extracts of $L$. multifida were more active compared to the other extracts, it is probably linked to its high phenolic composition. In a study by Ramdan et al. (2017), the aqueous extract of L. dentata has less activity compared to the hydromethanolic extracts of the same species studied, on the other hand the ethanolic extract (EC50 $346.5 \mathrm{mg} / \mathrm{mL}$ ) has more activity than that found in our work. This activity depended mainly on the type of solvent used for extraction (Nguyen et al. 2017), the extraction method as well as the geographical location of the plant and the harvest season (Chaouche et al. 2020).

\section{CONCLUSION}

In recent years, natural substances have seen an increasing interest in the medical field, in the pharmaceutical areas and food industries. In this context we were interested in the quantification of total phenols and in the antioxidant power of hydromethanolic extracts of the leaves and flowers of three species of Lavandula (L. dentata, L. multifida and L. stoechas). 
From the results obtained during this study, we noticed the presence of flavonoids and tannins in two parts of the three plants studied. The assay results of total polyphenols and the antioxidant activities in these extracts, show that the extract of the leaves $L$. multifida have a high level of polyphenols $(23 \pm 1.1$ mg EAG/g DW) and a significant antioxidant power compared to other extracts (DPPH ${ }^{\circ}$ assay the leaves: $I_{50} 300 \pm 8 \mu \mathrm{g} / \mathrm{ml}$ ), this activity remains low by comparing the $\mathrm{IC}_{50}$ values of the extracts with those of the positive controls (BHA). This may be due to the fact that the concentrations necessary to exert an antioxidant activity are higher for crude plant extracts than for pure and synthetic molecules.

Finally, these results obtained, in vitro, constitute only a first step in the search for natural substances which have antioxidant activity. It would be interesting to carry out other techniques and methods such as: Testing the antioxidant effect by other in vitro and in vivo methods, isolating and identifying chemical compounds responsible for the antioxidant activity of $L$. multifida.

Peer-review: Externally peer-reviewed.

Author Contributions: Conception/Design of Study- F.H.; Data Acquisition- F.H., T.M.C., I.G., O.B.; Data Analysis/Interpretation- F.H., T.M.C., I.G., O.B.; Drafting Manuscript- T.M.C., I.G.; Critical Revision of ManuscriptF.H.; Final Approval and Accountability- F.H., T.M.C., M.S., I.G., O.B.

Conflict of Interest: The authors have no conflict of interest to declare.

Financial Disclosure: Authors declared no financial support.

\section{REFERENCES}

- $\quad$ Adaszyńska-Skwirzyńska, M., \& Dzięcioł, M. (2017). Comparison of phenolic acids and flavonoids contents in various cultivars and parts of common lavender (Lavandula angustifolia) derived from Poland. Natural product research, 31(21), 2575-2580.

- $\quad$ Algieri, F., Rodriguez-Nogales, A., Vezza, T., Garrido-Mesa, J., Garrido-Mesa, N., Utrilla, M. P., González-Tejero, M.R., Casares-Porcel, M., Molero-Mesa, J., Del Mar Contreras, M., Segura-Carretero, A., Pérez-Palacio, J., Diaz, C., Vergara, N., Vicente, F., Rodriguez-Cabezas, ME., \& Galvez, J. (2016). Anti-inflammatory activity of hydroalcoholic extracts of Lavandula dentata L. and Lavandula stoechas L. Journal of Ethnopharmacology, 190, 142-158.

- Amara, N., Boukhatem, M. N., Ferhat, M. A., Kaibouche, N., Laissaoui, O., \& Boufridi, A. (2017). Applications potentielles de l'huile essentielle de lavande papillon (Lavandula stoechas L.) comme conservateur alimentaire naturel. Phytothérapie, 4, 1-9.

- Bachiri, L., Echchegadda, G., Ibijbijen, J., \& Nassiri, L. (2016). Etude phytochimique et activité antibactérienne de deux espèces de Lavande Autochtones Au Maroc:«Lavandula stoechas L. et Lavandula dentata L.». European Scientific Journal, 12(30), 313-333

- Bettaieb Rebey, I., Bourgou, S., Saidani Tounsi, M., Fauconnier, M. L., \& Ksouri, R. (2017). Etude de la composition chimique et de l'activité antioxydante des différents extraits de la Lavande dentée (Lavandula dentata). Journal of New Sciences Agriculture and Biotechnology, 39(2), 2096-2105.

- Bouharb, H., El Badaoui, K., Zair, T., El amri, J., Chakir, S., \& Alaoui, T. (2014). Sélection de quelques plantes médicinales du Zerhoun (Maroc centrale) pour l'activité antibactérienne contre Pseudomonas aeruginosa. Journal of Applied Biosciences, 78(1), 6685-6693.

- Bousta, D., \& Farah, A. (2020). A Phytopharmacological review of a Mediterranean plant: Lavandula stoechas L. Clinical Phytoscience, 6(1), 9.
Canlı, K., Yetgin, A., Benek, A., Bozyel, M. E., \& Murat Altuner, E. (2019). In Vitro Antimicrobial Activity Screening of Ethanol Extract of Lavandula stoechas and Investigation of Its Biochemical Composition. Advances in Pharmacological and Pharmaceutical Sciences, 2019, 1-6.

- $\quad$ Chaouche, T. M., Haddouchi, F., Boudjemai, O., \& Ghellai, I. (2020). Antioxidant and hemolytic activity of Ziziphus jujuba Mill and Rhamnus alaternus $L$ (Rhamnaceae) extracts from Algeria. Bulletin de la Société Royale des Sciences de Liège, 89, 1-14

- $\quad$ Chaouche, T.M., Haddouchi, F., Atik-Bekara, F., Ksouri, R., Azzi, R., Boucherit, Z., Tefiani, C., \& Larbat, R. (2015). Antioxidant, haemoIytic activities and HPLC-DAD-ESI-MSn characterization of phenolic compounds from root bark of Juniperus oxycedrus subsp. oxycedrus. Industrial Crops and Products, 64, 182-187

- Dif, M. M., Benyahia, M., Benali, F. T., Rahmani, M., \& Bouazza, S. (2017). Phenolic content and antioxidant activity of three Algerian species of lavenders. Phytothérapie, 15(6), 367-372.

- Ebrahimzadeh, M. A., Pourmorad, F., \& Bekhradnia, A.R. (2008). Iron chelating activity screening, phenol and flavonoid content of some medicinal plants from Iran. African Journal of Biotechnology, 7(18), 3188-3192

- El Hassouni, A., El Bachiri, A., \& Belbachir, C. (2019). Lavandula dentata Solid Residue from Essential Oil Industry. Journal of Essential Oil Bearing Plants, 22(6), 1601-1613.

- El-Hilaly, J., Hmammouchi, M., \& Lyoussi, B. (2003). Ethnobotanical studies and economic evaluation of medicinal plants in Taounate province (Northern Morocco). Journal of Ethnopharmacology, 86(2-3), 149-158.

- Haddouchi, F., Chaouche, T.M., \& Nourdinne, H. (2018). Screening phytochimique, activités antioxydantes et pouvoir hémolytique de quatre plantes sahariennes d'Algérie. Phytothérapie, 16(1), 254-262.

- Kala, C.P. (2015). Medicinal and aromatic plants: boon for enterprise development. Journal of Applied Research on Medicinal and Aromatic Plants, 2(4), 134-139.

Karabagias, I.K., Karabagias, V.K., \& Riganakos, K.A. (2019). PhysicoChemical Parameters, Phenolic Profile, In Vitro Antioxidant Activity and Volatile Compounds of Ladastacho (Lavandula stoechas) from the Region of Saidona. Antioxidants, 8(4), 80.

Ksouri, R., Falleh, H., Megdiche, W., Trabelsi, N., Hamdi, B., Chaieb, K., Bakhrouf, A., Magné, C., \& Abdelly, C. (2009). Antioxidant and antimicrobial activities of the edible medicinal halophyte Tamarix $g$ allica $\mathrm{L}$ and related polyphenolic constituents. Food and Chemical Toxicology, 47(8), 2083-2091.

- Maisuthisakul, P., Pongsawatmanit, R., \& Gordon, M. H. (2007). Assessment of phenolic content and free radical scavenging capacity of some Thai indigenous plants. Food Chemistry, 100(4), 1409-1418.

- Messaoud, C., Chograni, H., \& Boussaid, M. (2012). Chemical composition and antioxidant activities of essential oils and methanol extracts of three wild Lavandula L. species. Natural Product Research, 26(21), 1976-1984.

- Napoli, E., Siracusa, L., \& Ruberto, G. (2020). New Tricks for Old Guys: Recent Developments in the Chemistry, Biochemistry, Applications and Exploitation of Selected Species from the Lamiaceae Family. Chemistry \& Biodiversity, 17(3), e1900677.

- $\quad$ Nguyen, T. Q., Schmitz, A., Nguyen, T. T., Orlov, N. L., Böhme, W., \& Ziegler, T. (2011). Review of the genus Sphenomorphus Fitzinger, 1843 (Squamata: Sauria: Scincidae) in Vietnam, with description of a new species from northern Vietnam and southern China and the first record of Sphenomorphus mimicus Taylor, 1962 from Vietnam. Journal of Herpetology, 45(2), 145-154.

- $\quad$ Panuccio, M. R., Fazio, A., Papalia, T., \& Barreca, D. (2016). Antioxidant properties and flavonoid profile in leaves of Calabrian Lavandula multifida L., an autochthon plant of Mediterranean Southern regions. Chemistry \& Biodiversity, 13(4), 416-421 
- $\quad$ Ramchoun, M., Harnafi, H., Alem, C., Benlyas, M., Elrhaffari, L., \& Amrani, S. (2009). Study on antioxidant and hypolipidemic effects of polyphenol-rich extracts from Thymus vulgaris and Lavendula multifida. Pharmacognosy Research, 1(3), 106.

- Ramdan, B., Amakran, A., Bakrim, N., Vannier, B., Greche, H., \& Nhiri, M. (2017). Anti-glycation and radical scavenging activities of hydro-alcohol and aqueous extracts of nine species from Lamiaceae family. Journal of Medicinal Plants, 5(1), 331-345.
Soheili, M., \& Salami, M. (2019). Lavandula angustifolia biological characteristics: An in vitro study. Journal of Cellular Physiology, 234(9), 16424-16430.

- Sosa, S., Altinier, G., Politi, M., Braca, A., Morelli, I., \& Della Loggia, R. (2005). Extracts and constituents of Lavandula multifida with topical anti-inflammatory activity. Phytomedicine, 12(4), 271-277. 